\title{
When balanced for precursor fatty acid supply echium oil is not superior to linseed oil in enriching lamb tissues with long-chain $n-3$ PUFA
}

\author{
Soressa M. Kitessa ${ }^{1,2_{*}} \dagger$, Paul Young ${ }^{1,2}$, Greg Nattrass ${ }^{1,3}$, Graham Gardner ${ }^{1,4}$, Kelly Pearce ${ }^{1,4}$ \\ and David W. Pethick ${ }^{1,4}$ \\ ${ }^{1}$ Australian Cooperative Research Centre for Sheep Industry Innovation, Armidale, NSW 2350, Australia \\ ${ }^{2}$ CSIRO Livestock Industries, Private Bag 5, Wembley, WA 6913, Australia \\ ${ }^{3}$ South Australian Research and Development Institute (SARDI), Roseworthy Campus, JS Davies Building, Roseworthy, \\ SA 5371, Australia \\ ${ }^{4}$ School of Veterinary and Biomedical Sciences, Murdoch University, 90 South Street, Murdoch, WA 6150, Australia \\ (Submitted 9 June 2011 - Final revision received 2 September 2011 - Accepted 2 September 2011 - First published online 20 October 2011)
}

\section{Abstract}

Vegetable oils containing stearidonic acid (SDA, 18:4n-3) are considered better precursors of long-chain $n-3$ PUFA (LC $n-3$ PUFA) than those with only $\alpha$-linolenic acid (ALA, 18:3n-3). The present study re-examined this premise using treatments where added ALA from linseed oil was matched with ALA plus SDA from echium oil. Lambs $(n 6)$ were abomasally infused with saline (control (C), $25 \mathrm{ml})$, echium oil low $(\mathrm{EL}, 25 \mathrm{ml}$ ), echium oil high $(\mathrm{EH}, 50 \mathrm{ml})$, linseed oil low $(\mathrm{LL}, 25 \mathrm{ml})$ or linseed oil high $(\mathrm{LH}, 50 \mathrm{ml})$ for 4 weeks. The basal ration used was identical across all treatments. EPA $(20: 5 n-3)$ in meat increased from $6.5 \mathrm{mg}$ in the C lambs to $16 \cdot 8,17 \cdot 7,13.5 \mathrm{and} 11 \cdot 7$ (SEM 0.86$) \mathrm{mg} /$ $100 \mathrm{~g}$ muscle in the EL, EH, LL and LH lambs, respectively. For muscle DPA (docosapentaenoic acid; $22: 5 n$ - 3 ), the corresponding values were $14.3,22.2,18.618 .2$ and 19.4 (SEm 0.57$) \mathrm{mg} / 100 \mathrm{~g}$ muscle. The DHA (22:6n-3) content of meat was $5.8 \mathrm{mg} / 100 \mathrm{~g}$ in the C lambs and ranged from 4.53 to 5.46 (SEM 0.27 ) $\mathrm{mg} / 100 \mathrm{~g}$ muscle in the oil-infused groups. Total $n$-3 PUFA content of meat (including ALA and SDA) increased from $39 \mathrm{mg}$ to $119,129,121$ and 150 (SEM 12.3) $\mathrm{mg} / 100 \mathrm{~g}$ muscle. We conclude that both oil types were effective in enhancing the EPA and DPA, but not DHA, content of meat. Furthermore, we conclude that, when balanced for precursor $n-3$ fatty acid supply, differences between linseed oil and echium oil in enriching meat with LC $n$-3 PUFA were of little, if any, nutritional significance.

\section{Key words: $\alpha$-Linolenic acid: Echium oil: Lamb meat: Linseed oil: Stearidonic acid}

Meat is a major component of the Western-style diet, and it is also predicted that increased affluence in developing nations will entail increased consumption of meat ${ }^{(1)}$. Myers \& Kent $^{(1)}$ estimated that between 1997 and 2020, developing countries as a whole would increase their demand for meat by $92 \%$, and that the great bulk of this increase would be to serve new consumers. An $\mathrm{FAO}^{(2)}$ perspective on world agriculture also showed a $150 \%$ increase in per capita intake of meat in developing countries between the 1960s and 1990s, with a further $44 \%$ predicted increase between 1997-9 and 2030. The respective values for industrialised nations were 43 and $13 \%$, respectively ${ }^{(2)}$. We have previously argued that increasing the $n-3$ PUFA content of meat needs to be part of the global strategy to minimise the impact of chronic diseases $^{(3)}$. The challenge is to find complementary livestock feed ingredients that sufficiently improve the long-chain $n-3$ PUFA (LC $n-3$ PUFA) content of meat to the extent that the meat can be termed a 'source' or 'good source' of LC $n-3$ PUFA. In Australia ${ }^{(4)}$ and the European Union ${ }^{(5)}$, the cutoff points for 'source' and 'good source' claims are 30 and $60 \mathrm{mg}$ per serve, respectively.

The Australian lamb industry has currently invested in multiyear, multi-institutional national research programmes that aim to improve the nutritional and eating quality of lamb through genetics and nutrition $^{(6)}$. The present study was part of this national research initiative, and the specific objective of the present study was to compare the relative efficacy of linseed oil (with no stearidonic acid (SDA), 18:4n-3) and echium oil (SDA: $130 \mathrm{mg} / \mathrm{g}$ oil) in enriching lamb meat and tissue with EPA and DHA. The interest in SDA-containing oils is due to

\footnotetext{
Abbreviations: ALA, $\alpha$-linolenic acid; C, control; DPA, docosapentaenoic acid; EH, echium oil high; EL, echium oil low; GR, total tissue thickness over the twelfth rib, $110 \mathrm{~mm}$ out from the backbone; LA, linoleic acid; LC $n-3$ PUFA, long-chain $n$ - 3 PUFA; LH, linseed oil high; LL, linseed oil low; SDA, stearidonic acid.
}

*Corresponding author: S. M. Kitessa, fax +6108 83038841, email soressa.kitessa@csiro.au

† Present address: CSIRO Food and Nutritional Sciences, PO Box 10041, Adelaide BC 5000, Australia. 
the fact that in the LC $n-3$ PUFA biosynthetic pathway, SDA is the product of $\Delta-6$ desaturation of $\alpha$-linolenic acid (ALA, $18: 3 n-3)$, which makes it a step closer to EPA than ALA. It is thought that the desaturation of ALA to SDA is an inefficient and rate-limiting step in the biosynthesis of EPA and DHA in vertebrates $^{(7)}$. Previously, we have shown that echium oil was more effective than rapeseed oil in enriching poultry meat with EPA and docosapentaenoic acid (DPA) ${ }^{(3)}$. Rymer et $a l^{\left({ }^{(8)}\right.}$ also reported the superiority of SDA-enriched soyabean oil over conventional soyabean oil in improving the LC $n-3$ PUFA content of chicken meat. Both these studies and other studies that compared the efficacy of SDA-containing oils with ALA-containing oils as precursors of EPA and DHA were based on equal oil volume. In the present study, we aimed to test the efficacy of ALA- and SDA-containing oils at equal oil volume and equivalent total precursor $n$-3 fatty acid supply.

\section{Materials and methods}

\section{Oils and basal ration}

Linseed oil was obtained from a local supermarket. Echium oil was sourced from Croda Australia, Villawood, NSW, Australia (Product Name: Crossential SA14, Product Code SR03959/ SAMP). The basal ration was formulated to match the local commercial lamb finisher pellets. Each $\mathrm{kg}$ pellet was made up of oaten hay $(550 \mathrm{~g})$, barley grains $(280 \mathrm{~g})$, lupin grains $(100 \mathrm{~g})$, molasses $(50 \mathrm{~g})$ and mineral mix (SIROMIN $\AA$, $20 \mathrm{~g}$ ). SIROMIN $^{\circledR}$ was obtained from Compass Feeds Private Limited, (Mt Compass, South Australia, Australia). The mineral mix ${ }^{(9)}$ contained $\mathrm{Na} 169 \mathrm{~g} / \mathrm{kg}, \mathrm{K} 99 \mathrm{~g} / \mathrm{kg}$, Ca $65 \mathrm{~g} / \mathrm{kg}, \mathrm{S} 46 \mathrm{~g} / \mathrm{kg}, \mathrm{P}$ $16 \mathrm{~g} / \mathrm{kg}, \quad \mathrm{Mg} \quad 4 \mathrm{~g} / \mathrm{kg} ; \quad \mathrm{Fe} 3800 \mathrm{mg} / \mathrm{kg}, \quad \mathrm{Mn} 660 \mathrm{mg} / \mathrm{kg}, \quad \mathrm{Zn}$ $940 \mathrm{mg} / \mathrm{kg}, \quad \mathrm{Cu} 120 \mathrm{mg} / \mathrm{kg}$, Co $75 \mathrm{mg} / \mathrm{kg}, \quad$ B $26 \mathrm{mg} / \mathrm{kg}$, Mo $36 \mathrm{mg} / \mathrm{kg}, \mathrm{Ni} 18 \mathrm{mg} / \mathrm{kg}, \mathrm{V} 14 \mathrm{mg} / \mathrm{kg}, \mathrm{Cr} 11 \mathrm{mg} / \mathrm{kg}$, and $\mathrm{Se}$ $5 \mathrm{mg} / \mathrm{kg}$. The crude protein, crude fat, neutral-detergent fibre, acid-detergent fibre, hemicellulose and lignin contents of the basal ration were $134,23,530,231,350$ and $32 \mathrm{~g} / \mathrm{kg}$, respectively. It contained $11960 \mathrm{~kJ} / \mathrm{kg}$ DM of metabolisable energy.

\section{Lambs and surgical preparation}

All animal handling, surgical procedures and sample collection procedures were approved by the CSIRO Animal Ethics Committee in accordance with the National Health and Medical Research Council's guidelines ${ }^{(10)}$. A total of thirty-five Poll-Dorset $\times$ Merino male lambs were purchased from a commercial farm (Hillcroft Farms, Popanyinning, Western Australia, Australia). After 2 weeks of acclimatisation to indoor housing, the sheep were clipped from the transverse processes to the midline of the abdomen on the right side in preparation for surgery. Surgery involved insertion of a polyethylene catheter with an internal diameter of $1.5 \mathrm{~mm}$ ( $1 \mathrm{~m}$ in length) into the abomasums, ensuring $4-5 \mathrm{~cm}$ of the catheter was present in the abomasum beyond the cuff of the catheter. A Kendall Tomcat 3.5 inch $(8.9 \mathrm{~cm})$ French catheter flange was placed on the exterior surface of the abomasum and anchored with two simple interrupted sutures. The free end of the catheter was attached to the skin using a Kendall Tomcat 3.5 inch French catheter flange, and secured to the skin with two simple interrupted sutures. Post-operative analgesia and prophylactic antibiotic cover was provided according to the guidelines approved by the Animal Ethics Committee. Following surgery, the animals were monitored closely including assessment of daily food intake and rectal temperatures. The lambs were given 4 weeks to recover before the start of infusion.

\section{Experimental design, infusion and daily management of lambs}

There were five infusion treatments: control (C, saline water; $0.154 \mathrm{~mol} \mathrm{NaCl}$ per litre of distilled water); echium oil low (EL, $25 \mathrm{ml}$ ); echium oil high (EH, $50 \mathrm{ml}$ ); linseed oil low (LL, $25 \mathrm{ml}$ ); linseed oil high (LH, $50 \mathrm{ml}$ ). The five infusates were prepared using the formulation in Table 1. All infusates contained vitamin $\mathrm{E}$ at a level to provide individuals with $1000 \mathrm{IU}(1000 \mathrm{mg}) / \mathrm{d}$. The vitamin $\mathrm{E}$ used was from International Animal Health Products, Huntingwood, NSW, Australia (vitamin E 50\% (w/w), DL- $\alpha$-tocopheryl acetate, $500 \mathrm{IU}(500 \mathrm{mg}) / \mathrm{g}$ ). Coconut oil was used to balance the oil infusion treatments for total oil, total n-3 PUFA, ALA and SDA content (Table 1). Lambs were offered their daily allocation of pellets in individual pens at 08.00 hours. Feed residue was collected each morning and weighed. For the first 2 weeks, the lambs were given half of their allocated oil doses in two portions at 08.00 and 16.00 hours. In the second 2 weeks, each animal was given its full dose infusate in two aliquots. Infusion was delivered using a $50 \mathrm{ml}$ syringe. To prevent clogging of catheters, oil infusion was followed

Table 1. Composition of the treatment oils used for abomasal infusion of lambs

\begin{tabular}{|c|c|c|c|c|c|c|c|}
\hline \multirow[b]{2}{*}{ Treatment } & \multicolumn{4}{|c|}{ Oils } & \multicolumn{3}{|c|}{ Fatty acids } \\
\hline & Linseed (ml) & Echium (ml) & Coconut (ml) & Total (ml) & ALA $(18: 3 n-3 ; g)$ & SDA $(18: 4 n-3 ; g)$ & Total $n-3(\mathrm{~g})$ \\
\hline Control & 0.00 & 0.00 & 0.00 & 0.0 & 0.00 & 0.00 & 0.00 \\
\hline \multicolumn{8}{|l|}{ Echium } \\
\hline Low & 0.00 & 25.00 & 0.00 & $25 \cdot 0$ & 7.50 & 3.25 & 10.75 \\
\hline High & 0.00 & $50 \cdot 00$ & 0.00 & $50 \cdot 0$ & $15 \cdot 00$ & 6.50 & 21.50 \\
\hline \multicolumn{8}{|l|}{ Linseed } \\
\hline Low & 19.56 & 0.00 & 5.44 & $25 \cdot 0$ & $10 \cdot 75$ & 0.00 & $10 \cdot 75$ \\
\hline High & $39 \cdot 10$ & 0.00 & 10.90 & $50 \cdot 0$ & 21.50 & 0.00 & 21.50 \\
\hline
\end{tabular}

ALA, $\alpha$-linolenic acid; SDA, stearidonic acid. 
by a $5 \mathrm{ml}$ saline injection into the catheter. Drinking-water was available ad libitum within each pen. Lambs were weighed on arrival and once per week during acclimatisation, recovery from surgery and infusion periods.

\section{Slaughter and sampling}

At slaughter, organ weights (heart and liver), hot carcass weights and GR readings were obtained in the abattoir room (GR refers to the total tissue thickness over the twelfth rib, $110 \mathrm{~mm}$ out from the backbone $\left.{ }^{(11)}\right)$. Initial muscle $\mathrm{pH}$ was measured on $M$. longissimus dorsi immediately after the carcass was moved into the chiller, and ultimate $\mathrm{pH}$ was measured $24 \mathrm{~h}$ later in the same muscle in the boning room. We collected samples of $M$. longissimus dorsi, $M$. semimembranosus, $M$. semitendinosus and subcutaneous fat samples from the rump region of each carcass. All samples were transported under ice and stored in freezers $\left(-20^{\circ} \mathrm{C}\right)$ until analysis. Each muscle sample was cut into smaller portions and minced using a kitchen food processor, before subsampling for intramuscular fat and fatty acid analysis. Faecal samples for the fatty acid assay were obtained by emptying the rectum.

\section{Lipid analysis}

Muscle subsamples for intramuscular fat analysis were dried in a microwave for $20 \mathrm{~min}$ at defrost setting $\left(2-2.5^{\circ} \mathrm{C} / \mathrm{min}\right)$. The level of intramuscular fat in muscle was determined on $3 \mathrm{~g}$ of the dried sample using a Soxtec 2050 extraction unit (Foss Tecator; Foss Pacific, Sydney, NSW, Australia) and following Foss application note 3127: Extraction of Fat in Meat and Meat Products. A sample from each animal was extracted in duplicate and the extraction was repeated if the two duplicates differed by more than $5 \%$. Fatty acid composition was determined by direct synthesis of fatty acid methyl esters ${ }^{(12)}$. Briefly, $1 \mathrm{~g}$ subsample of ground wet muscle was hydrolysed by incubating in methanol containing potassium hydroxide $(10 \mathrm{M})$, then fatty and methyl esters (FAME) were synthesised by further incubation with sulphuric acid (24M). FAME were then extracted with hexane for analysis on a gas chromatograph fitted with a BPX 70 capillary column $(50 \mathrm{~m}$ in length, internal diameter of $0.32 \mathrm{~mm}$, bonded-phase film thickness of $0.25 \mathrm{~mm}$; SGE Australia, Sydney, NSW, Australia). The carrier gas was $\mathrm{He}$, at a flow rate of $140 \mathrm{kPa}$. The injector and detector temperatures were set at 220 and $250^{\circ} \mathrm{C}$, respectively. The temperature programme was as follows: initial temperature of $120^{\circ} \mathrm{C}$ held for $1 \mathrm{~min}$, increased at $20^{\circ} \mathrm{C} / \mathrm{min}$ to $250^{\circ} \mathrm{C}$, and then held at that temperature for $20 \mathrm{~min}$. Peak identification and confirmation procedures were similar to those reported earlier ${ }^{(13)}$. Briefly, the internal standard used with each extraction was methylnonadecanoate (19:0, Sigma product no. N5377; Sigma-Aldrich, St Louis, MO, USA), and the standard FAME mixtures of $\mathrm{C} 4-\mathrm{C} 24$ were also obtained from Sigma-Aldrich (Supelco product no. 18919). With each GC analysis run, one certified reference sample (Menhaden oil, Supelco Catalogue no. 4-7116) of known fatty acid profile was included every fifty samples. The fatty acid profiles of whole blood, liver, heart and faecal samples were determined following the same GC method. In all cases, the absolute value of each fatty acid as mg per weight/volume was generated based on the area of the internal standard peak and its known concentration in the sample.

\section{Data analysis}

Final live weight and carcass data were analysed using ANOVA in Genstat ${ }^{\circledR}$ (VSN international Ltd, Hemel Hempstead, Herts, UK) ${ }^{(14)}$. Changes in the fatty acid composition of whole blood across the three sampling points over $28 \mathrm{~d}$ were analysed using repeated-measures ANOVA in Genstat ${ }^{\circledR}$. Muscle, liver, heart and faecal fatty acid composition data were analysed using ANOVA in Genstat ${ }^{\circledR}$. Initially, when analysing fatty acid data for muscle samples from longissimus dorsi, semimembranosus and semitendinosus, we performed analysis of muscle $\times$ treatment interaction. This was not significant for any of the major fatty acids. For brevity, only data for longissimus dorsi are presented. Fatty acid data for subcutaneous, omental and perirenal fat depots were analysed but not presented, as they did not present a different treatment hierarchy from that observed on muscle data.

\section{Results}

Intake, live weight and carcass yield

The daily DM intake in the week preceding the beginning of infusion was 1080 (SEM 15) g/head. In the C, EL, EH and LL lambs, it did not significantly deviate from this mean intake/ head per d during the infusion period. In contrast, in the LH lambs, it was 736, 955, 717 and 762 (SEM 50) g/head per d after 1, 2, 3 and 4 weeks of supplementation, respectively. Despite the identical oil volumes, DM intake was suppressed in the $\mathrm{LH}$, but not $\mathrm{EH}$, lambs. The latter had a similar intake to the $\mathrm{C}$ lambs. On the day infusion begun, the mean live weight was $37 \cdot 5,38 \cdot 0,36 \cdot 8,38.6$ and $36 \cdot 2$ (SEM 0.31 ) $\mathrm{kg}$ for the C, EL, EH, LL and LH lambs, respectively. The corresponding average live weights of lambs at slaughter (after $28 \mathrm{~d}$ ) were $40 \cdot 0,40 \cdot 3,38 \cdot 2,40 \cdot 5$ and $36 \cdot 6(\operatorname{sem} 0 \cdot 39) \mathrm{kg}$. The mean liveweight gains (excluding LH) ranged $1.4-2.5 \mathrm{~kg}$ over the 4 weeks, which were equivalent to $50-89 \mathrm{~g} / \mathrm{d}$. The LH group had significantly lower (by about $2 \mathrm{~kg}$ ) final live weight than the other treatment groups, but the difference was not reflected in hot carcass yield (18.0-19.3 (SEM 0.22) kg) or dressing percentage (46.4-49.4 (SEM $0 \cdot 39) \%$ ). Ultimate $\mathrm{pH}$ (5.7-5.8 (SEM 0.02)), GR $(6 \cdot 0-7 \cdot 5 \quad(\operatorname{sem} 0 \cdot 30) \mathrm{mm})$, liver weight (487-579 (SEM 12.8) g) and heart weight (177-199 (SEM 2.8) g) did not differ between the treatments.

\section{Changes in n-3 fatty acid composition of whole blood}

The changes observed in blood $n$ - 3 PUFA content are presented in Fig. 1. In all the oil-infused groups, there was a sharp rise in ALA content over the first 2 weeks, which tended to plateau over the second 2 weeks (Fig. 1(a)). The LH group had the sharpest rise in ALA content and reached 



Fig. 1. Changes in individual $n-3$ fatty acids in the whole blood of lambs in response to abomasal infusion with saline (control (C), $-\infty)$ ), echium oil low (EL

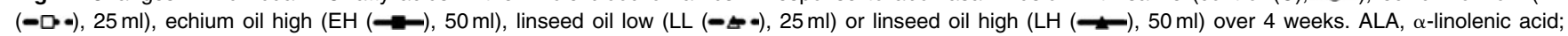
SDA, stearidonic acid; DPA, docosapentaenoic acid.

significantly higher $(P<0 \cdot 001)$ maximum both at weeks 2 and 4. The level of SDA in blood was barely detectable in lambs on treatments that did not contain SDA (i.e. C, LL and LH); it also did not show any change in these groups over the three sampling points (Fig. 1(b)). In contrast, lambs infused with echium oil had a sharp rise in the SDA content of their whole blood over the first 2 weeks. The SDA content of blood from the EH group plateaued after the second week. Whole blood EPA content significantly increased $(P<0.01)$ in all lambs infused with oil, but was virtually unchanged in the $\mathrm{C}$ lambs (Fig. 1(c)). There was no significant difference between the oils or doses at week 2, but at week 4, The EL group had significantly higher EPA content than all the other treatments. The latter was also the case for blood DPA content (Fig. 1(d)). In the case of blood DHA content, the low doses of each oil treatment reached a significantly higher maximum than the other treatments at week 4 (Fig. 1(e)).

\section{Fatty acid composition of muscle}

There was no muscle $\times$ treatment interaction and treatment hierarchies in the $n$-3 PUFA content of muscle were 
Table 2. Fatty acid composition ( $\mathrm{mg} / 100 \mathrm{~g}$ muscle) of the longissimus dorsi of lambs abomasally infused with saline (control; C), echium oil low (EL, $25 \mathrm{ml}$ ), echium oil high (EH, $50 \mathrm{ml}$ ), linseed oil low (LL, $25 \mathrm{ml}$ ) or linseed oil high (LH, $50 \mathrm{ml})$ over 4 weeks

(Mean values with their standard errors)

\begin{tabular}{|c|c|c|c|c|c|c|c|}
\hline \multirow[b]{2}{*}{ Fatty acid } & \multicolumn{5}{|c|}{ Treatment diets } & \multirow[b]{2}{*}{ SEM } & \multirow[b]{2}{*}{$P$} \\
\hline & $\mathrm{C}$ & EL & $\mathrm{EH}$ & LL & $\mathrm{LH}$ & & \\
\hline $10: 0$ & $5 \cdot 51$ & $7 \cdot 20$ & 5.33 & 5.93 & 6.06 & 1.304 & 0.852 \\
\hline $12: 0$ & 1.64 & $2 \cdot 29$ & 2.02 & 1.91 & 3.66 & 0.553 & 0.076 \\
\hline $14: 0$ & $39 \cdot 0$ & $53 \cdot 8$ & $43 \cdot 4$ & $42 \cdot 2$ & $49 \cdot 0$ & $8 \cdot 12$ & 0.686 \\
\hline $16: 0$ & 503 & 585 & 493 & 446 & 450 & $82 \cdot 0$ & 0.935 \\
\hline $17: 0$ & 0.00 & $2 \cdot 37$ & 2.00 & 0.00 & 0.00 & 1.423 & 0.546 \\
\hline $18: 0$ & 464 & 507 & 439 & 462 & 471 & $81 \cdot 2$ & 0.982 \\
\hline $20: 0$ & $2 \cdot 44$ & 2.93 & 2.39 & $2 \cdot 66$ & $2 \cdot 88$ & 0.493 & 0.885 \\
\hline Total SFA & 1021 & 1165 & 991 & 1043 & 1058 & 171.9 & 0.958 \\
\hline $14: 1$ cis-9 & 1.46 & 1.96 & 1.62 & 1.42 & 1.63 & 0.220 & 0.453 \\
\hline $16: 1$ cis-9 & 3.55 & 4.98 & 3.83 & $3 \cdot 62$ & 4.74 & 3.76 & 0.618 \\
\hline $17: 1$ & 1.24 & $1 \cdot 19$ & 0.92 & 0.65 & $1 \cdot 12$ & 0.312 & 0.525 \\
\hline $18: 1 \mathrm{cis}-9$ & 972 & 906 & 789 & 905 & 878 & $160 \cdot 2$ & 0.934 \\
\hline $20: 1$ & $3 \cdot 61$ & 4.08 & 3.53 & $3 \cdot 29$ & 2.96 & 0.560 & 0.670 \\
\hline $18: 2 n-6(\mathrm{LA})$ & 153 & 170 & 172 & 150 & 172 & $10 \cdot 81$ & 0.356 \\
\hline $18: 3 n-6(G L A)$ & $1.57^{\mathrm{a}}$ & $11 \cdot 6^{\mathrm{b}}$ & $14 \cdot 7^{\mathrm{b}}$ & $1 \cdot 12^{\mathrm{a}}$ & $1.09^{a}$ & 1.922 & $<0.001$ \\
\hline $20: 3 n-6$ (GDLA) & $4 \cdot 81^{a}$ & $9 \cdot 43^{\mathrm{b}}$ & $9 \cdot 70^{\mathrm{b}}$ & $4 \cdot 34^{a}$ & $3.96^{a}$ & 0.392 & $<0.001$ \\
\hline $20: 4 n-6$ (ARA) & $54 \cdot 8^{\mathrm{b}}$ & $54 \cdot 8^{\mathrm{b}}$ & $47 \cdot 3^{\mathrm{a}}$ & $46 \cdot 8^{\mathrm{a}}$ & $45 \cdot 1^{\mathrm{a}}$ & $2 \cdot 177$ & 0.004 \\
\hline Total $n-6$ & 216 & 249 & 246 & 203 & 224 & 18.5 & 0.075 \\
\hline $18: 3 n-3(\mathrm{ALA})$ & $12 \cdot 8^{a}$ & $64 \cdot 3^{\mathrm{b}}$ & $76 \cdot 4^{\mathrm{b}}$ & $79.9^{b}$ & $113 \cdot 3^{c}$ & $10 \cdot 35$ & $<0.001$ \\
\hline $18: 4 n-3(\mathrm{SDA})$ & $0.00^{\mathrm{a}}$ & $8.94^{\mathrm{b}}$ & $11 \cdot 0^{\mathrm{b}}$ & $0.26^{\mathrm{a}}$ & $0.44^{\mathrm{a}}$ & 1.695 & $<0.001$ \\
\hline $20: 5 n-3$ (EPA) & $6 \cdot 49^{\mathrm{a}}$ & $16 \cdot 8^{b, c}$ & $17 \cdot 7^{\mathrm{C}}$ & $13 \cdot 5^{\mathrm{b}}$ & $11 \cdot 7^{\mathrm{b}}$ & 1.207 & $<0.001$ \\
\hline $22: 5 n-3$ (DPA) & $14 \cdot 3^{\mathrm{a}}$ & $22 \cdot 2^{\mathrm{c}}$ & $18 \cdot 6^{\mathrm{b}}$ & $18 \cdot 2^{\mathrm{b}}$ & $19 \cdot 4^{\mathrm{b}}$ & 0.952 & $<0.001$ \\
\hline $22: 6 n-3(\mathrm{DHA})$ & $5 \cdot 84^{a, b}$ & $5 \cdot 46^{\mathrm{a}}$ & $4.57^{\mathrm{a}}$ & $7 \cdot 10^{\mathrm{b}}$ & $4.53^{\mathrm{a}}$ & 0.553 & 0.014 \\
\hline$E P A+D H A$ & $12 \cdot 3^{\mathrm{a}}$ & $22 \cdot 3^{\mathrm{c}}$ & $22 \cdot 3^{\mathrm{C}}$ & $20 \cdot 6^{\mathrm{b}, \mathrm{c}}$ & $16 \cdot 3^{a, b}$ & 1.477 & $<0.001$ \\
\hline $\mathrm{EPA}+\mathrm{DPA}+\mathrm{DHA}$ & $26 \cdot 6^{a}$ & $44 \cdot 5^{\mathrm{c}}$ & $40 \cdot 9^{b, c}$ & $38.9^{\mathrm{b}}$ & $33 \cdot 4^{\mathrm{b}}$ & $2 \cdot 185$ & $<0.001$ \\
\hline Total $n-3$ & $39^{a}$ & $119^{\mathrm{b}}$ & $129^{b}$ & $121^{\mathrm{b}}$ & $150^{\mathrm{b}}$ & $12 \cdot 26$ & $<0.001$ \\
\hline
\end{tabular}

LA, linolenic acid; GLA, $\gamma$-linolenic acid; DGLA, dihomo- $\gamma$-linolenic acid; ARA, arachidonic acid; ALA, $\alpha$-linolenic acid; SDA, stearidonic acid; DPA, docosapentaenoic acid. ${ }^{\mathrm{a}, \mathrm{b}, \mathrm{c}}$ Mean values within a row with unlike superscript letters were significantly different.

similar among longissimus dorsi, semimembranosus and semitendinosus. Where statistical differences were detected, the magnitudes of differences were very small to be nutritionally relevant. For instance, for DPA and DHA, differences between muscles were significant at $P=0.007$ and $P=0.036$, respectively. The mean DPA content of the three muscles was $17.8,19.5$ and $19.6 \mathrm{mg} / 100 \mathrm{~g}$ for M. longissimus dorsi, $M$. semimembranosus and $M$. semitendinosus, respectively. We have thus chosen to present the M. longissimus dorsi data for brevity. The fatty acid composition of $M$. longissimus dorsi is summarised in Table 2. There were no significant changes in the concentrations of SFA across the treatments (Table 2). The total SFA content also did not differ between the treatments and ranged from 991 to $1165 \mathrm{mg} / 100 \mathrm{~g}$ muscle (Table 3). The major MUFA across all treatments was oleic (18:1 cis-9), which also showed no significant difference among the treatments (Table 2). The content of linoleic acid (LA) was also similar between the treatments. In contrast, muscle $\gamma$-linolenic acid (GLA) and dihomo- $\gamma$-linolenic acid (DGLA) contents were, respectively, about 10 - and 2-fold higher $(P<0.001)$ in the echium-infused lambs than the other treatments (Table 2). Arachidonic acid (ARA) was higher in the muscles of lambs under the $\mathrm{C}$ and EL treatments. The total $n-6$ PUFA content of muscles was similar $(P=0.08)$ across the treatments (Table 2), and ranged 203-249 mg/ $100 \mathrm{~g}$ muscle.
With respect to the $n$-3 PUFA enrichment of lamb muscle, all oil-infused lambs had greater ALA/100 g muscle than the C lambs (Table 2). Within the oil-infused groups, the LH lambs had the highest ALA content $(113 \mathrm{mg} / 100 \mathrm{~g})$ in their muscle. Muscle SDA content was highest in the echium oil-infused groups (EL and $\mathrm{EH}$ ) than the other three treatments (C, LL and $\mathrm{LH}$ ). There was no difference in muscle SDA content between the $\mathrm{C}$ lambs and lambs infused with linseed oil. The EPA content of muscle was significantly improved by both linseed oil and echium oil (Table 2). There was no indication of the dose effect as the values within the oil treatments were similar. Similarly, the DPA content of lamb muscles was significantly improved by both oils; the $\mathrm{C}$ lambs had about $4 \mathrm{mg} / 100 \mathrm{~g}$ less DPA (Table 2). The LL lambs (at $7 \cdot 10 \mathrm{mg}$ / $100 \mathrm{~g}$ ) had a significantly higher DHA content in their muscle than the other oil-infused group of lambs (4.53$5.46 \mathrm{mg} / 100 \mathrm{~g}$ ), although not significantly different from the C lambs. The total EPA plus DHA content of muscle from the oil-infused lambs $(20 \cdot 6-22 \cdot 3 \mathrm{mg} / 100 \mathrm{~g})$, except for the LH lambs $(16.3 \mathrm{mg})$, was significantly higher than the $\mathrm{C}$ lambs $(12 \cdot 3 \mathrm{mg} / 100 \mathrm{~g})$. Total LC $n-3$ PUFA (i.e. EPA + DPA + DHA) contents were all above the $30 \mathrm{mg} / 100 \mathrm{~g}$ muscle except for the C lambs (in which it was $26.6 \mathrm{mg} / 100 \mathrm{~g}$ muscle; Table 2). Generally, oil infusion was more than tripled the total $n$-3 PUFA content of muscle (39 mg $v$. 119-150 mg/ $100 \mathrm{~g}$ muscle; Table 2). 
Table 3. Changes in the liver and heart $n-3$ fatty acid composition (mg/ $100 \mathrm{~g}$ tissue) of lambs in response to abomasal infusion with saline (control; C), echium oil low (EL, $25 \mathrm{ml}$ ), echium oil high $(\mathrm{EH}, 50 \mathrm{ml})$, linseed oil low (LL, $25 \mathrm{ml})$ or linseed oil high (LH, $50 \mathrm{ml}$ ) over 4 weeks

(Mean values with their standard errors)

\begin{tabular}{|c|c|c|c|c|c|c|c|}
\hline & \multicolumn{5}{|c|}{ Diets } & \multirow[b]{2}{*}{ SEM } & \multirow[b]{2}{*}{$P$} \\
\hline & C & EL & $\mathrm{EH}$ & LL & LH & & \\
\hline \multicolumn{8}{|l|}{ Liver } \\
\hline $18: 3 n-3$ & $17 \cdot 0^{\mathrm{a}}$ & $150 \cdot 3^{b}$ & $219 \cdot 5^{\mathrm{b}}$ & $165 \cdot 0^{\mathrm{b}}$ & $4623 \cdot 0^{c}$ & 34.60 & $<0.001$ \\
\hline $18: 4 n-3$ & $0.86^{\mathrm{a}}$ & $9 \cdot 82^{\mathrm{b}}$ & $15 \cdot 1^{\mathrm{b}}$ & $2.06^{\mathrm{a}}$ & $4.02^{\mathrm{a}}$ & $2 \cdot 66$ & 0.002 \\
\hline $20: 5 n-3$ & $29 \cdot 1^{\mathrm{a}}$ & $98.9^{b}$ & $94 \cdot 20^{\mathrm{b}}$ & $104 \cdot 5^{b}$ & $98 \cdot 8^{\mathrm{b}}$ & $10 \cdot 07$ & $<0.001$ \\
\hline $22: 5 n-3$ & $110 \cdot 4^{a}$ & $270 \cdot 2^{d}$ & $203 \cdot 8^{c}$ & $182 \cdot 3^{\mathrm{c}}$ & $138 \cdot 5^{\mathrm{b}}$ & 11.04 & $<0.001$ \\
\hline $22: 6 n-3$ & $128 \cdot 2^{b}$ & $140 \cdot 8^{b, c}$ & $100 \cdot 2^{\mathrm{a}}$ & $168 \cdot 7^{c}$ & $95 \cdot 4^{\mathrm{a}}$ & 10.38 & $<0.001$ \\
\hline \multicolumn{8}{|l|}{ Heart } \\
\hline $18: 3 n-3$ & $18.59^{\mathrm{a}}$ & $94.48^{b}$ & $131.91^{b}$ & $141.67^{\mathrm{b}}$ & $206 \cdot 24^{c}$ & 13.97 & $<0.001$ \\
\hline $18: 4 n-3$ & $0.80^{\mathrm{a}}$ & $6.02^{b}$ & $8.98^{\mathrm{b}}$ & $1.04^{a}$ & $1.05^{\mathrm{a}}$ & 1.85 & 0.006 \\
\hline $20: 5 n-3$ & $11 \cdot 84^{\mathrm{a}}$ & $63 \cdot 62^{c}$ & $47.43^{b, c}$ & $35 \cdot 64^{a, b}$ & $34.00^{\mathrm{a}, \mathrm{b}}$ & 9.09 & 0.005 \\
\hline $22: 5 n-3$ & $16 \cdot 94^{\mathrm{a}}$ & $28.07^{c}$ & $26 \cdot 49^{\mathrm{b}, \mathrm{c}}$ & $24 \cdot 64^{\mathrm{b}, \mathrm{c}}$ & $22 \cdot 76^{\mathrm{b}}$ & 0.95 & $<0.001$ \\
\hline $22: 6 n-3$ & 17.96 & 17.92 & 15.45 & 23.95 & $15 \cdot 81$ & 1.06 & $<0.088$ \\
\hline
\end{tabular}

a,b,c,d Mean values within a row with unlike superscript letters were significantly different.

\section{Fatty acid composition of adipose tissue}

There was no fat depot $x$ dietary treatment interaction for any of the fatty acids that we measured on adipose tissue. Across all three fat depots, the oil-infused lambs had significantly greater $(P<0.001)$ concentrations of ALA and SDA in their adipose tissue than the $C$ lambs. Across the three fat depots, the mean ALA content of adipose tissue was 234, 1366, 2240, 1514 and 2098 for the C, EL, EH, LL and LH lambs, respectively (SEM $395 \mathrm{mg}$ ). The corresponding values for SDA were $8.4,281,389,10$ and $15 \mathrm{mg} / 100 \mathrm{~g}$ fat (SEM $25.9 \mathrm{mg}$ ). With respect to LC $n-3$ PUFA (EPA, DPA and DHA), there was no clear trend of hierarchy across the fat depots or in the individual fat depot that could be related to oil type or precursor supply. For instance, the EPA contents across the fat depots were 59, 105, 99, 79 and 55 (SEM $10 \cdot 7) \mathrm{mg} / 100 \mathrm{~g}$ for the C, EL, EH, LL and LH lambs, respectively. The respective values for DHA were 13, 31, 21, 28 and $13(\mathrm{sem} 3.3) \mathrm{mg} / 100 \mathrm{~g}$ fat. None of them fitted with the expected $\mathrm{C}<\mathrm{LL}<\mathrm{LH}<\mathrm{EL}<\mathrm{EH}$ trend. Curiously, EPA did not differ between the treatments $(P=0.73)$.

\section{Changes in n-3 PUFA contents of liver and heart}

In both heart and liver, the precursor fatty acids (ALA and SDA) were significantly raised by oil infusion (Table 3). As with the adipose tissue data, there was not a consistent trend of hierarchy in the LC $n$ - 3 PUFA content of liver or heart that reflected oil dose or oil type. For instance, the EPA content of liver tissue was similar across all oil-infused lambs. Surprisingly, DHA in liver was even similar between the $\mathrm{EH}$ and $\mathrm{C}$ lambs (Table 3). Heart tissue samples from the EH lambs had similar EPA to those of the LL and LH lambs; samples from the EL lambs had the highest EPA content. Though not statistically significant, the values for EPA in heart tissue for lambs infused with echium oil were higher than those for linseed oil.
Total fat and n-3 and n-6 PUFA concentrations of faeces at slaughter

The fat contents of faecal DM were 0.72, 0.88, 2.55, 0.99 and $2 \cdot 18$ (SEM 0.436) g/100 g for the C, EL, EH, LL and LH lambs, respectively. There were no significant differences among the diets in the concentrations of the precursor dietary fatty acids ALA $(P=0 \cdot 174)$ or SDA $(P=0.766)$. The EPA content of faecal matter was also similar across the treatments. On the other hand, faecal matter from the two high-dose groups had slightly higher concentrations of DPA and DHA than that from the other three groups $(P<0.05)$. For instance, DPA contents in faecal DM were 4.0, 2.9, 9.2, 4.9 and 8.4 (SEM 1.67) g/100 g total fatty acids for the C, EL, EH, LL and LH lambs, respectively.

\section{Discussion}

\section{Intake, live weight and carcass yield}

Despite the decrease in intake and live-weight change observed on lambs infused with the high-dose linseed oil, the other lambs achieved adequate intake to support liveweight gains of $50-89 \mathrm{~g} / \mathrm{d}$ over the 4 weeks. This was very much below the daily live-weight gains of more than $200 \mathrm{~g} / \mathrm{d}$ targeted by lamb finishing systems in the region ${ }^{(15)}$. Since the metabolisable energy value of the basal ration was optimal, the poor live-weight gain was most probably due to the physiological depression of intake arising from the invasive surgery as well as lipid infusion. Interestingly, the difference in final live weight did not lead to different carcass yields. Demirel et al. ${ }^{(16)}$ also found no difference in hot or cold carcass weight in lambs supplemented with palm oil distillate, linseed oil or a combination of linseed oil and fish oil. The hot carcass yield of $18-19 \mathrm{~kg}$ achieved was near the bottom end of the industry target range for lamb carcasses from cross-breeds ${ }^{(15)}$. It was also similar to the hot carcass yield $(19-20 \mathrm{~kg})$ achieved by Poll-Dorset $\times$ Merino cross 
lambs fed similar basal mix plus rumen-protected linseed $\mathrm{oil}^{(17)}$. As in the previous study ${ }^{(17)}$, linseed oil supplementation in the present study did not have an impact on such carcass attributes as dressing percentage, ultimate $\mathrm{pH}$ and GR depth. Hence, the muscle and tissue enrichments of LC $n$-3 PUFA discussed below were achieved without an adverse effect on carcass attributes.

\section{Fatty acid composition of blood}

The most notable overall trend observed across whole blood $n$-3 PUFA was that the precursor fatty acids in blood (ALA and SDA) tended to plateau after the second week, while the product fatty acids, EPA and DHA, and to a lesser extent DPA, were still trending up between weeks 2 and 4. This suggests that increasing the duration of supplementation could most probably have resulted in greater enrichment of tissues with LC $n-3$ PUFA. While the possibility of this cannot be discounted, our previous study involving duration of rumen-protected linseed oil supplementation showed modest gain beyond 3 weeks of supplementation ${ }^{(18)}$. It is worth noting the absence of SDA in lambs that were not supplemented with echium oil, although the ones supplemented with linseed oil showed elevated levels of LC $n-3$ PUFA further up the chain from SDA (e.g. EPA and DHA). It suggests that the amount of SDA from the conversion of ALA in linseed was within the lambs' capacities to quickly convert it to LC $n$-3 PUFA, whereas the significant rise in whole blood SDA in the echium oil-supplemented groups most probably exceeded the lambs' capacities to quickly convert it to LC $n-3$ PUFA. If that was the case, optimisation of the efficiency of conversion of ALA to EPA and DHA in vertebrates requires more effort than overcoming the so-called rate-limiting step of the ALA-to-SDA conversion.

\section{Enrichment of muscle with long-chain n-3 PUFA}

The changes observed in the amounts of the major SFA were similar to previous studies ${ }^{(17,18)}$. In both meat ${ }^{(17,18)}$ and dairy $^{(13)}$ animals, $n-3$ PUFA supplementation did not cause any change in the SFA content of livestock products. The changes in muscle LC $n$-3 PUFA composition observed in the present study were similar to those observed previously using rumen-protected linseed $\mathrm{oil}^{(17,18)}$. Generally, greater changes in muscle LC $n$-3 PUFA were observed in the amounts of precursor fatty acids (ALA and SDA) contained in the added oil than the product LC $n-3$ PUFA (EPA and DHA). While both oil types markedly improved the total mg EPA plus DHA that can be obtained from a $100 \mathrm{~g}$ lean muscle serve, there were very little differences in this nutritionally important parameter between oils or doses. It is interesting to note that when the sum of LC $n$-3 PUFA included DPA, rather than just EPA plus DHA, all meat from the oil-supplemented lambs easily surpassed the $30 \mathrm{mg}$ per serve cut-off point for 'source claim' set by Food Standards Australia and New Zealand $\left(\right.$ FSANZ) ${ }^{(4)}$. The absence of oil or dose effect in the total LC $n$-3 PUFA content of muscle was at odds with our anticipation of increased enrichment of muscle with LC $n-3$ PUFA with oil that contains SDA plus ALA as opposed to that which only contained ALA. In a well-designed human study, James et $a l .{ }^{(19)}$ provided a direct comparison of ALA, SDA and EPA in human subjects by using encapsulated ethyl esters of each fatty acid. Their results showed that SDA was 3.1- to 3.9-fold more effective than ALA in enriching erythrocyte and plasma phospholipids with EPA. We did not find equivalent contrasting EPA levels between the echium oil and linseed oil treatments in any of the tissues that we measured.

There are two published studies which also compared AZA and SDA-containing oils in chicken. The first study by Kitessa \& Young ${ }^{(3)}$ showed significantly greater enrichment of leg and breast muscles with LC $n$-3 PUFA when broilers were supplemented with echium oil (ALA + SDA oil) than rapeseed oil (ALA oil). Rymer et al. ${ }^{(8)}$ similarly showed that chicken meat enrichment with LC $n$-3 PUFA was greater when GM soyabean oil with enhanced SDA content (ALA + SDA oil) was fed to chicken than with supplementation of conventional soyabean oil (ALA only). In the latter study, the mg EPA per $100 \mathrm{~g}$ muscle was doubled in breast muscle (12 v. $28 \mathrm{mg}$ ) and 10-fold increased in leg muscle ( $5 v .53 \mathrm{mg}$ ) when SDAsoya was used as opposed to conventional soyabean oil. Because the present study supplied oil post-ruminally, it is unlikely that the difference between the chicken results and our lamb results is due to differences in biohydrogenation in the rumen. We suggest that previous studies were confounded in their comparison of ALA and SDA oils because they used equal oil volume instead of using both equal oil volume and equivalent $n$-3 fatty acid supply. The present study is the first to attempt to adjust total dietary $n$ - 3 fatty acid supply between oils that were considered as the sources of ALA and SDA. In the study by Kitessa $\&$ Young ${ }^{(3)}$, total added $n$ 3 PUFA coming from ALA + SDA was $317 \mathrm{mg} / 100 \mathrm{~g}$ for the rapeseed diet and $1165 \mathrm{mg} / 100 \mathrm{~g}$ feed for the echium oil diet. The respective values for the study by Rymer et al. ${ }^{(8)}$ were $291 v .1349 \mathrm{mg}$ and $347 v .1407 \mathrm{mg} / 100 \mathrm{~g}$ feed in their starter and finisher rations. Hence, it can be argued that the chicken studies were confounded by having a different total $n$-3 supply that exaggerated the efficacy of SDA-containing oils as precursors of EPA.

Bernal-Santos et al. $^{(20)}$ also reported greater enrichment of milk fat with LC $n-3$ PUFA when SDA-soyabean oil was used. Their study was also based on oil volume equivalence rather than precursor fatty acid supply, with the result that there was a 5-fold difference in precursor supply between ALA + SDA oil (SDA-soya) and the conventional oil (soyabean oil). Furthermore, Lemke et $a l .{ }^{(21)}$ reported greater $n$-3 index in human subjects supplemented with SDA-enriched soyabean oil compared with those supplemented with the conventional soyabean oil. A closer look at the treatment oils showed that the conventional soyabean oil had $5.8 \mathrm{~g} / 100 \mathrm{~g}$ ALA, while SDA-soya had $10.7 \mathrm{~g} / 100 \mathrm{~g}$ ALA and $28.2 \mathrm{~g} / 100 \mathrm{~g}$ SDA. Hence, the total precursor supply was $5 \cdot 8 \mathrm{~g} / 100 \mathrm{~g}$ in the conventional soyabean oil and $38.9 \mathrm{~g} / 100 \mathrm{~g}$ total fatty acids in SDA-soya. We suggest that comparisons based on equivalent oil volume with a marked difference in precursor supply exaggerate the efficacy of SDA-containing oils in enriching tissue with EPA and DHA. It is given that these SDA-soya studies 
show how much more effective the new oil is compared with the conventional soyabean oil. However, the relative merit of this oil compared with other existing oils that supply equivalent $n$-3 fatty acids (as ALA) remains to be determined. In our view, results with currently commercially available SDA oils (SDA-soya and echium oil) do not match the marked differences achieved using ethyl ester of each fatty acid. More comparisons based on equivalent precursor supply are required to optimise the benefits of SDA oils as a means of increasing EPA and DHA supply. To our knowledge, the present study is the only study that compared an ALA plus SDA-containing oil with ALA-containing oil by balancing both oil volume and total added dietary $n-3$ supply (ALA + SDA) across the treatments.

\section{Fatty acid composition of adipose tissue, liver, heart and faecal DM}

The adipose tissue fatty acid data have clearly shown that there was no preferential accretion of LC $n$-3 PUFA away from muscle tissue. Similarly, Demirel et al. ${ }^{(16)}$ showed less accretion of LC $n-3$ PUFA into subcutaneous adipose tissue than into lamb muscle. In fact, they did not detect EPA or DHA in the subcutaneous fat of lambs supplemented with linseed oil or a linseed-fish oil mix. Our previous report ${ }^{(22)}$ on lambs fed preformed EPA and DHA (protected tuna oil) also did not show preferential accretion of EPA and DHA in adipose tissue compared with muscle. Hence, the inefficient conversion of ALA and SDA into LC $n$-3 PUFA in muscle appears to have very little to do with competition for precursors from other pools. Since most consumers tend to trim fat, the enrichment of adipose tissue with LC $n-3$ PUFA is of limited nutritional significance.

Interestingly, the marked dose response in liver ALA content did not lead to increased EPA content in liver. It is also not clear why the marked changes observed in the contents of SDA in the heart and liver of echium oil-infused lambs failed to lead to greater concentration of at least EPA, if not DHA, in their tissues than those infused with linseed oil. Comparison of accretion of precursor (ALA) and product (EPA) fatty acids in the polar and neutral lipid fractions of lamb liver from Demirel et $a l^{(16)}$ data showed that under the ideal high vitamin E supplementation treatment, the ALA content of liver in linseed oil-supplemented groups increased by an average of (across two breeds) 152 and 156\% in the polar and neutral fractions over that of palm oil-supplemented groups. The respective increases in EPA were about 65 and 67\%. This fits with our observation of marked increases in liver ALA content with increased dose of linseed oil that did not elicit an equivalent marked increase in the EPA content of this tissue. Other notable aspects of heart and liver LC $n-3$ PUFA when compared with the other tissues were as follows: (1) the lack of response of heart DPA and DHA to oil infusion, oil type or dose, and (2) the significant reductions incurred in liver DPA and DHA when the doses of both oils were increased.

The measurement of faecal fat and fatty acid content showed that the low dose used was within the range that can be effectively metabolised by these lambs. This was shown by the similarity in faecal fat content between the $\mathrm{C}$ and low-dose lambs of either oil. The marked increase in the fat content of faecal DM when the oil doses were doubled, and the suppression of intake and live-weight gain in some of the sheep at the higher dose suggested that there was very limited scope for using higher doses of these oils to achieve a higher LC $n$-3 PUFA in meat. In practice, oils are supplied in the diet, and without an effective ruminal protection, the current doses will have a major impact on intake and performance. There were consequent increases in faecal EPA and DHA content but these are of no nutritional consequence.

We did not attempt to balance the $n-6: n-3$ ratio in the present study. Other authors ${ }^{(23)}$ have suggested that the ratio of $n-6: n-3$ (more specifically LA:ALA) has an impact on the biosynthesis of EPA and DHA from ALA and/or SDA. First, there is no reason why the background $n-6$ supply from the basal ration could have disadvantaged echium oil to any greater extent than it did linseed oil. Second, studies in human subjects have suggested that it is the absolute amount of ALA rather than the LA:ALA ratio that influences the conversion of ALA to LC $n$-3 PUFA ${ }^{(24,25)}$. We suggest that the background $n$-6 supply from the basal ration was the least likely reason for the lack of difference between the two oils in enriching meat with LC $n$-3 PUFA.

\section{Summary and conclusions}

The present study is the first to compare ALA- and SDA-containing oils on equal total added dietary ALA plus SDA content, as opposed to previous studies where comparisons were based on total oil volume. Across five different tissues (blood, muscle, adipose, heart and liver), we have shown that the gain in enhanced EPA and DHA content due to the use of SDA-containing oil, as opposed to ALA-only oil, was so small as to be nutritionally relevant. That is, there was no marked difference in the $\mathrm{mg}$ of EPA plus DHA per $100 \mathrm{~g}$ muscle to be obtained when lambs were supplemented with echium oil as opposed to linseed oil. This conclusion contradicts previous reports where SDA-containing oils were reported to be superior to ALA-only oils in enriching muscle with LC $n-3$ PUFA (EPA and DHA). We suggest that those studies were based on equal oil volume, which entailed markedly different total precursor fatty acid supply. Further research with labelled isotopes is needed to confirm the relative value of SDA-containing oils in enriching livestock products with LC $n-3$ PUFA before such oils can be considered superior to conventional ALA-containing oils. We conclude that both linseed oil and echium oil supplementation were similarly effective in enriching lamb meat with LC $n$-3 PUFA. We recommend that future assessment of precursors of LC n-3 PUFA using similar designs to ours should also include isotopes of precursor fatty acids as well as assessment of expressions of genes in the $n-3$ PUFA biosynthetic pathway.

\section{Acknowledgements}

This study was funded by the Australian Cooperative Research Centre for Sheep Industry Innovation, Armidale, NSW, Australia. All authors declare that they have no conflict of interest. 
S. M. K. contributed to the conception, design, conduct of the experiment and analysis of the data for publication. D. W. P. was the Meat Program leader in the Sheep CRC and contributed to the conception and design of the experiment. G. N., K. P. and G. G. were involved in the conception, design of the experiment as well as in the preparation of animals during surgery and slaughter. P. Y. was in charge of feed formulation, animal feeding, all the laboratory assays and preparation of the data for publication.

\section{References}

1. Myers N \& Kent J (2003) New consumers: the influence of affluence on the environment. Proc Natl Acad Sci U $S$ A 100, 4963-4968.

2. Food and Agricultural Organisation (FAO) (2003) World Agriculture: towards 2015/2030. An FAO perspective. (Jelle Bruinsma) London: Earthscan Publication Ltd.

3. Kitessa SM \& Young P (2009) Echium oil is better than rapeseed oil in enriching poultry meat with $n-3$ polyunsaturated fatty acids, including eicosapentaenoic acid and docosapentaenoic acid. Br J Nutr 101, 705-715.

4. Food Standards Australia New Zealand (2003) Australia New Zealand Food Standards Code. Standard 1·2·8. Nutrition Information Requirements. Canberra: Food Standards Australia New Zealand (FSANZ). http://www.foodstandards. gov.au/thecode/foodstandardscode.cfm.

5. European Food Standards Authority (2010) Commission Regulation (EU) No 116/2010 of 9 February 2010 amending Regulation (EC) No 1924/2006 of the European Parliament and of the Council with regard to the list of nutrition claims. Official J Euro Union L37, 16-18.

6. Hopkins DL, Jacob RH, Ball AJ, et al. (2009) The CRC for Sheep Industry Innovation- measurement of new and novel meat traits. In Proceedings of the 55th International Congress of Meat Science and Technology, pp. 23-26. Frederiksberg, Denmark: University of Copenhagen.

7. Huang YS, Smith RS, Redden PR, et al. (1991) Modification of liver fatty acid metabolism in mice by $n-3$ and $n-6$ D6desaturase substrates and products. Biochim Biophys Acta 1082, 319-327.

8. Rymer C, Hartnell GF \& Givens DI (2011) The effect of feeding modified soybean oil enriched with C18:4n-3 to broilers on the deposition of $n-3$ fatty acids in chicken meat. Br J Nutr 105, 866-878.

9. White CL, Masters DG, Peter DW, et al. (1992) A multi element supplement for grazing sheep. 1. Intake, mineral status and production responses. Aust J Agric Res 43, 795-808.

10. National Health and Medical Research Council (2004) Australian Code of Practice for the Care and Use of Animals for Scientific Purposes, 7th ed. Canberra: Australian Government.
11. Hopkins DL, Ponnampalam EN \& Warner RD (2007) Predicting the composition of lamb carcases using alternative fat and muscle depth measures. Meat Sci 78, 400-405.

12. O'Fallon JV, Busboom JR, Nelson ML, et al. (2007) A direct method for fatty acid methyl ester synthesis: application to wet meat tissues, oils and feedstuffs. J Anim Sci 85, 1511-1521.

13. Kitessa SM, Gulati SK, Simos GC, et al. (2004) Supplementation of grazing dairy cows with rumen-protected tuna oil enriches milk fat with $n-3$ fatty acids without affecting milk production or sensory characteristics. Br J Nutr 91, 271-277.

14. Lawes Agricultural Trust (2000) GenStatw Release 4.2. Reference Manual. Oxford: VSN International Ltd.

15. Pethick DW, Banks RG, Hales J, et al. (2006) Australian prime lamb - a vision for 2020. Int J Sheep Wool Sci 54, 66-73.

16. Demirel G, Wachira AM, Sinclair LA, et al. (2004) Effects of dietary $n-3$ polyunsaturated fatty acids, breed and dietary vitamin $\mathrm{E}$ on the fatty acid of lamb muscle, liver and adipose tissue. Br J Nutr 91, 551-565.

17. Kitessa SM, Liu S, Briegel J, et al. (2010) Effects of intensive or pasture finishing in spring and linseed supplementation in autumn on the omega- 3 content of lamb meat and its carcass distribution. Anim Prod Sci 50, 130-137.

18. Kitessa SM, Williams A, Gulati SK, et al. (2009) Influence of duration of supplementation with ruminally protected linseed oil on the fatty acid composition of feedlot lambs. Anim Feed Sci Technol 151, 228-239.

19. James MJ, Ursin VM \& Cleland LG (2003) Metabolism of stearidonic acid in human subjects: comparison with the metabolism of other $n-3$ fatty acids. Am J Clin Nutr 77, $1140-1145$.

20. Bernal-Santos G, O'Donnell AM, Vicini JL, et al. (2010) Hot topic: enhancing omega-3 fatty acids in milk fat of dairy cows by using stearidonic acid-enriched soybean oil from genetically modified soybeans. J Dairy Sci 93, 32-37.

21. Lemke SL, Vicini JL, Su H, et al. (2010) Dietary intake of stearidonic acid-enriched soybean oil increases the omega3 index: randomised, double-blind clinical study of efficacy and safety. Am J Clin Nutr 92, 766-775.

22. Kitessa SM, Gulati SK, Ashes JR, et al. (2001) Effects of feeding tuna oil protected against hydrogenation in the rumen on growth and $n$-3 fatty acid content of lamb fat and muscle. Aust J Agric Res 52, 433-437.

23. Chan JK, McDonald BE, Gerrard JM, et al. (1993) Effect of dietary $\alpha$-linolenic acid and its ratio to linoleic acid on platelet and plasma fatty acids and thrombogenesis. Lipids $\mathbf{2 8}$, 811-817.

24. Goyens PLL, Spilker ME, Zock PL, et al. (2006) Conversion of $\alpha$-linolenic acid in humans is influenced by the absolute amounts of $\alpha$-linolenic acid and linoleic acid in the diet and not by their ratio. Am J Clin Nutr 84, 44-53.

25. Stanley JC, Elsom RL, Calder PC, et al. (2007) UK Food Standards Agency workshop Report: the effects of the dietary $n-6: n-3$ fatty acid ratio on cardiovascular health. Br J Nutr 98, 1305-1310. 